\title{
Potential Hospital Location Selection using AHP: A Study in Rural India
}

\author{
Debmallya Chatterjee \\ Research scholar in the department of applied \\ mathematics in Indian School of Mines, Dhanbad, \\ India
}

\begin{abstract}
Selecting a location for a potential hospital often decides the success or the failure of such a facility. It is thus important to assess the locations from multiple dimensions before selecting the site. This paper focuses on the multi factor evaluation of hospital sites using Analytical Hierarchy process (AHP)and evaluates three potential rural hospital sites in India. This study considered three major factors and eleven sub factors in the evaluation. Findings show that among the sub factors, cost of land, population density and proximity to public transport evolved as the three most significant sub factors.
\end{abstract}

\section{General Terms}

Multi criteria decision making

\section{Key words}

Hospital location, AHP, multi factor evaluation, pair wise comparison, selection, expert opinion

\section{INTRODUCTION}

The growing population of a country always leads to the demand of new healthcare facilities and India is not an exception. With a growing economy lot of private health care facilities are coming up but mostly catering to the upper and upper middle class of the society. For the lower and lower middle class the facilities are very limited especially in the rural areas. From the WHO report it can be seen that the number of beds per 10000 population in India is only 9 (inpatient and maternity), much less than even Bhutan, Thailand, Malaysia and Nepal whereas the global standard is 30 . One may argue that these countries are smaller in size but even bigger countries like china is well ahead with 42 beds per 10000 citizens [28].

The above situation amplifies the need for new hospitals to be set up by the Governments for the poorer sections of the society who cannot spend a huge amount in healthcare. It is true that the absence of quality medical personnel is a genuine concern, but this only cannot guarantee the quality of the service provided to the society [24]. Physical access matters significantly and thus the selection of the location for the facility becomes a strategic issue as it is related to the medical service quality [15]. The success of such a facility depends on how it attracts the potential patients [10] and selection of the location must address issues related to environmental factors, economic, distance and social conveniences or inconveniences [26]. Because of the structure and the multicriteria nature of the hospital site selection decisions, this sort of decision making attracts personal and subjective analysis than objective analysis [6].

Studies are available on health care facility location and the travel time methodology is one of the prominent techniques used by the researchers across the globe ([12];[5]; [8]; [14]). This analysis requires extensive amount of data related to cost

\author{
Bani Mukherjee \\ Professor, Department of Applied Mathematics, \\ Indian School of Mines, Dhanbad, Jharkhand, India
}

grid or travel time and in most of these research works that data was providedby the concerned department of transportation. In Indian context this is a real problem. Moreover this modeling uses Zip codes which often contain geographic data error that leads to wrong population totals when modeled using area based methodology [27].

Vahidnia et al. also argued that because of the multi-criteria nature of the problem, the planners needed an analysis tool that can help in making a rational location selection capturing both subjective and objective evaluation [26]. This need inspired the researchers use analytical hierarchy process (AHP), a well-known technique in multi-criteria decision making (MCDM) [20]. AHP and it extended versions have been widely used in medical and non-medical decision making likeproject and technology selection, human resource selection, health care evaluation and policy and vendor selection ([15]; [10]; [13];[14]; [23]). Some researchers also used AHP and extended AHP for hospital site selection in international arena. Wu et al. used AHP and sensitivity analysis in location selection of Taiwanese hospitals to ensure competitive advantage. This piece of work provides valuable inputs for planners in standardizing the hospital location selection process [29].Vahidnia et al. used fuzzy AHP with GIS for optimal hospital site selection in Tehran urban area with a focus on pollution, travel time and cost[26]. Soltani et al. used a two stage fuzzy MCDM in selecting a location for hospital in Shiraj metropolitan area, Iran where the researchers tried to address the subjective decision making problem in MCDM by the use of AHP and GIS [24].Although there are studies available in hospital site selection using AHP or its extended form in countries other than India, almost all these works are done on an urban area. Based on the review of existing literature it can be inferred that no study has been done in rural India where AHP is used as a location selection tool. This piece of work attempts to address this gap in literature by assessing potential hospital sites in rural India using AHP. The objective is to see how well AHP can capture the qualitative differences existing among the alternative locations across different dimensions and help the planners in selecting an appropriate hospital location. For convenience in computation the result is illustrated using a case of three alternative locations namely Pandabeswar, faridpur and Kanksa in Durgapur sub division of West Bengal, India.

\section{THEORETICAL BACKGROUND}

\subsection{Analytical hierarchy process}

AHP proposed by Saatyin 1980 is one of the widely accepted tools that can be used in prioritizing alternatives based on multiple criteria. It is widely used in decision making situations where difficulties arise in generating importance of the factors using the qualitative responses [22]. Because of its intuitive appeal and flexibility, many organizations use AHP for making major policy decisions [1]. There are numerous applications of AHP in multi criteria decision making across 
different fields of study where the researchers provided evidences of the efficacy of AHP as a multi-criteria decision making tool involving subjective as well as objective evaluation ([2]; [4]; [7]; [13]; [3]; [9];[25]; [30]; [16];[29]).

AHP method involves certain steps[20]:

1) Based on the objective, lay out the overall hierarchy of the decision problem. This hierarchy exposes the various factors to be considered as well as the various alternatives in the decision. There may be multiple levels within the hierarchy based on the sub factors available under each factor.

2) Both qualitative and quantitative factors can be compared using pair wise comparisons, which generates factor weights. Factor weights are numerical values quantifying the importance of the factor in the decision.

3) Check the consistency ratios of the pair wise comparison matrices to ensure consistency in judgments. A matrix failing to satisfy the consistency test is rejected.

4) The alternatives are compared with respect to the factors or sub factors in the hierarchy and the scores are aggregated to obtain overall rating of an alternative.

\section{METHODOLOGY}

\subsection{Respondent selection}

Since the analytical hierarchy process is mainly based on a subjective decision making method,it requires reliable inputs for its efficacy and consistency. Inconsistent inputs can lead to rejection of the entire set of data during consistency test[19]. This character of AHP asks 'expert opinion' for consistent factor weight evaluations. In this hospital site selection problem the selected experts are medical doctors having more than fifteen years of experience in the field of hospital or health care administration and projectsand are quite acquainted with all the three alternative locationsin the Durgapur sub-division of West Bengal, India. A set of questionnaires were provided to the experts requested to do pair wise comparisons among factors (or sub factors) and identify the level of importance of one (factor or sub factor) over the other using the linguistic scale mentioned by Saatyin Table 1 [20].

Once the responses are captured using the questionnaires from 12 experts,an attempt has been made to generate consensus among the expert's opinion.Incase of significant response variation the average value is considered whereas in case of extreme divergencethe outlier is ignored.

Table 1:Pair wise comparison scale

\begin{tabular}{|l|l|c|}
\hline \multicolumn{1}{|c|}{ Verbal judgment } & \multicolumn{1}{|c|}{ Explanation } & Number \\
\hline Extremely Un-Important (EXUI) & A criterion is strongly inferior to another & $1 / 5$ \\
\hline Moderately Un-Important (MUI) & A criterion is slightly inferior to another & $1 / 3$ \\
\hline Equally Important (EI) & Two factor contribute equally & 1 \\
\hline Moderately Important (MI) & $\begin{array}{l}\text { Judgment slightly favor one criterion } \\
\text { over another }\end{array}$ & 3 \\
\hline Extremely Important (EXI) & $\begin{array}{l}\text { Judgment strongly favor one criterion } \\
\text { over another }\end{array}$ & 5 \\
\hline
\end{tabular}

Source: adopted from Saaty (1980)

\subsection{Identification of factors and sub factors for evaluating alternative locations}

A number of researchers who voiced for multi factor evaluation of a hospital site recommended a wide range of site selection criteria. Vahinia et al. (2008) considered distance from arterial routes, Travel time, contamination, land cost and population density as the set of factors for evaluation, Soltani talked about distance to major roads, distance to other medical centers, population density and parcel size of the land. In the optimal site selection for Taiwanese hospitals, Wu et al. considered, population size, age, density, governmental policies, capital, labour and land where Schuurman et al.discussed the importance of socio demographics of the service area, proximity to future expansion, space apart from travel time and population density([29], [21]). Based on the prominence in the available literature and opinions of the experts consulted, this study considers three major factors and eleven sub factors in the evaluation of hospital sites in India. The factors and sub factors are summarized in Table 2.

Table 2: Major factors and sub factors

\begin{tabular}{|c|c|}
\hline Major Factor & Sub Factors \\
\hline \multirow{4}{*}{ ([24]; [18]; [26]; [30]) } & Cost of land \\
\hline & Land Topography \\
\hline & Land ownership \\
\hline & Running/ Maintenance cost \\
\hline \multirow{2}{*}{$\begin{array}{l}\text { Population characteristics } \\
\text { ([24]; [21]; [26]; [29]) }\end{array}$} & Population density \\
\hline & Education \\
\hline
\end{tabular}




\begin{tabular}{|l|c|}
\hline \multirow{4}{*}{$([26] ;[24] ;[18])$} & Economic condition \\
\hline \multirow{2}{*}{ Location } & Proximity to Public transport \\
\cline { 2 - 2 } & Space for future construction \\
\cline { 2 - 2 } & Availability of existing infrastructure \\
\cline { 2 - 2 } & Proximity to market \\
\hline
\end{tabular}

\subsection{Building the hierarchy of the decision problem}

The hierarchy in AHP [20] starts with the objective or goal of the decision problem. The factors and sub factors responsible for evaluation of alternative hospital sites are placed in subsequent levels next to the objective. The ultimate level contains the alternative sites to be evaluated. When it comes to pair wise comparison, the factors are compared with themselves whereas the sub factors under each factor are only compared. In the cases of the alternatives, they are compared with respect to each of the sub factors available in the study. Figure 3 describes the hierarchy of the site selection problem.

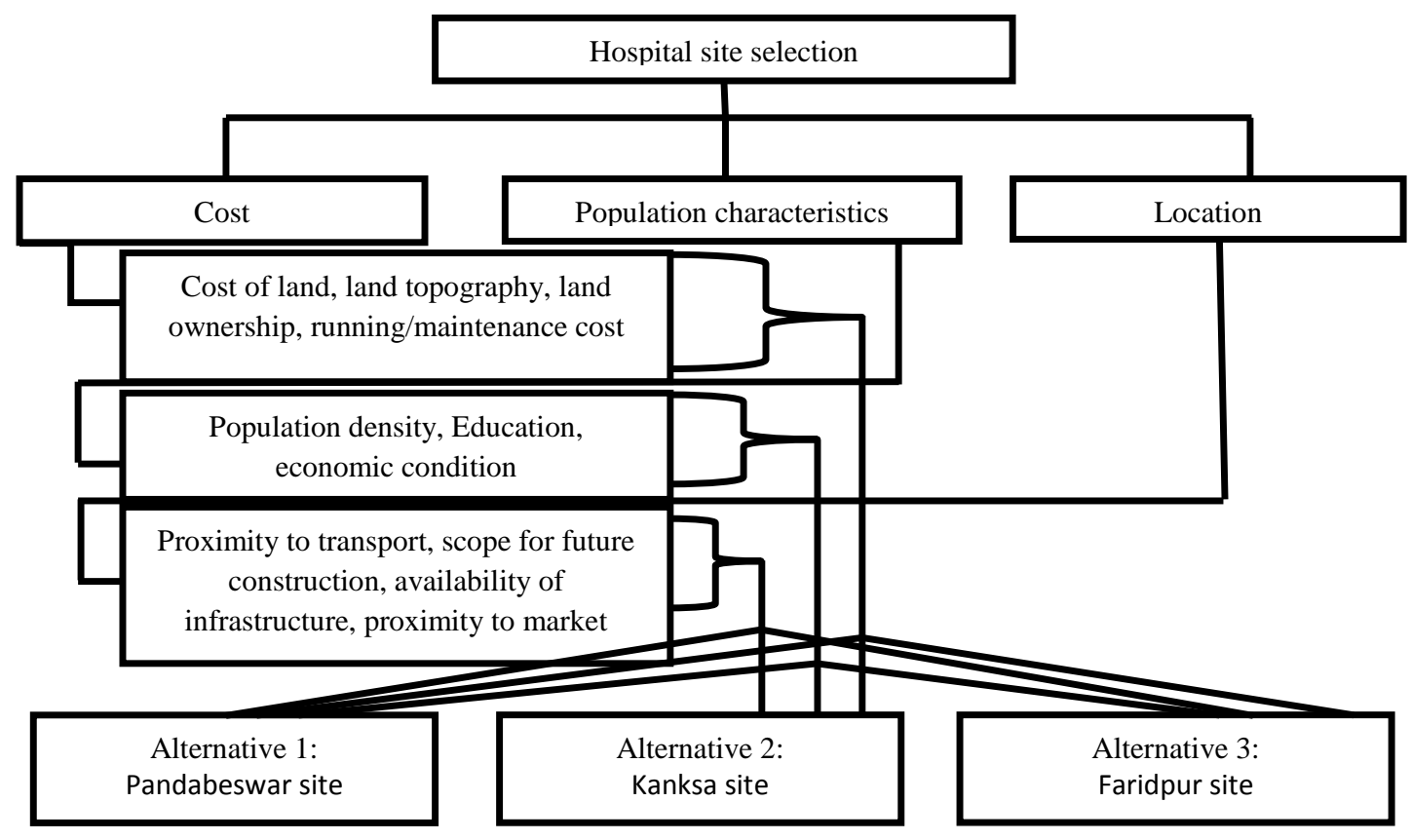

Figure 3: Hierarchy of the hospital site selection problem

\subsection{Study area}

The study area for this hospital site selection problem is in Durgapur sub division, district of Burdwan, West Bengal, India. Three rural locations namely Faridpur, Kanksa and Pandabeswar are selected as the potential hospital sites and denoted byHS1, HS2 and HS3 respectively. From the medical facility and population of the district of Burdwan, West
Bengal (http://www.bardhaman.gov.in/health/medifaci.html and http://www.bardhaman.gov.in/census/popliterate.html) one can see that in spite of a population of more than a lakh in each location, no hospital exists. The condition in terms of bed per 1000 population is even worse than that of the nation's average. Table 3 depicts the detail of the three alternate locationsand why needed a hospital badly([11], [17]).

Table 3:Population and hospital detail of the study area

\begin{tabular}{|l|r|r|r|r|}
\hline Area & Populations & Hospitals & Health center & Doctors* \\
\hline PANDABESWAR (HS3) & 146445 & 0 & 4 & 4 \\
\hline FARIDPUR (HS1) & 108619 & 0 & 2 & 3 \\
\hline KANKSA (HS2) & 151255 & 0 & 5 & 7 \\
\hline
\end{tabular}




\subsection{Generation of factor (or sub factor) scores and alternative scores}

In order to generate importance of the factors considered in the study and their contribution in the selection of a location for a potential hospital factor weight or factor scores are generated. To generate these factor (or sub factor)and alternative scores, two sets of questionnaire containing 18 and 33 questions were administered to the experts. The responses were captured using the scale mentioned already in Table 1. The factor (sub factor) and scores for thealternatives are obtained using the following steps:
Step 1: Calculate the relative weights of the factors compared through the matrix and calculate the column average of the row averages. $\lambda_{\text {average }}$ indicates the column average value.

Step 2: Compute the consistency index (CI) for each matrix of order $\mathrm{n}$ by the formulae:

$\mathrm{CI}=\left(\lambda_{\text {average }}-\mathrm{n}\right) /(\mathrm{n}-1)$.

Step 3: The consistency ratio (CR) is then calculated using the formulae: $\mathrm{CR}=\mathrm{CI} / \mathrm{RI}$, where RI is a known Random Index. Tables 4 show the value of the random index (RI) [19]. This consistency test validates the responses taken into the model. A response is valid if the value of CR is found to be less than 0.1 .

Tables 4:Random index (RI) table

\begin{tabular}{|l|l|l|l|l|l|l|l|l|}
\hline $\mathrm{n}$ & 3 & 4 & 5 & 6 & 7 & 8 & 9 & 10 \\
\hline R.I & 0.58 & 0.89 & 1.12 & 1.25 & 1.35 & 1.42 & 1.46 & 1.49 \\
\hline
\end{tabular}

\subsection{Generating overall score for alternatives}

The weights of the different factors and sub factors considered in the study are evaluated afterthe responses are tested for consistency. Here each of the sub factor weights are multiplied to the corresponding factor weights to generate overall weights $S_{l}$. The overall score of $m^{\text {th }}$ alternative is obtained by $\mathrm{A}_{\mathrm{m}}$ in equation (1)

$$
A_{m}=\sum_{l=1}^{N} s_{l} \times a_{m}
$$

where $\boldsymbol{S}_{\boldsymbol{l}}$ is the weight of $l^{\text {th }}$ sub factor and $\boldsymbol{a}_{\boldsymbol{m l}}$ is the weight of $\boldsymbol{m}^{\text {th }}$ alternative with respect to $l^{\text {th }}$ sub factor.

\section{RESULTS AND DISCUSSION}

After the responses from the experts are taken using the questionnaires the summery sheet is sent to the expert for reconsidering their previous opinions if any with a communication that the entire process is repeated to arrive at a consensus. Once the responses are finally captured and converted into numeric value, the datais fitted in matrices to generate factor sub factor and alternative scores using the steps mentioned in section 3.5.From Figure 4, one can see that among the major factors cost is considered three times more important than the other two major factors. Table 8 portrays the impact of the sub factors within the main factors and also their overall impact in selecting a candidate location. Cost of land, population density are contributing more than 50\%, proximity to public transport around $45 \%$ within the major factors whereas proximity to market contributes to $27 \%$ under location. From the overall impact of a sub factor in the study, one can see that cost of land alone has an impact at the level of $36.5 \%$ whereas the next highest impact is of population density at a level of $13 \%$. Figure 5 depicts the scores obtained by the alternative sites with respect to each sub factor. Moreover from figure 5 it can also be understood that both Faridpur and Kanksa are in a better position than Pandabeswar against most of the sub factors except population density and economic condition. From the final score in Figure 6, although Kanksa emerges as the best potential location in this study with a score of 0.3837 , but Faridpur is very near with a score of 0.3762 .

Figure 4: Weight of the main factors

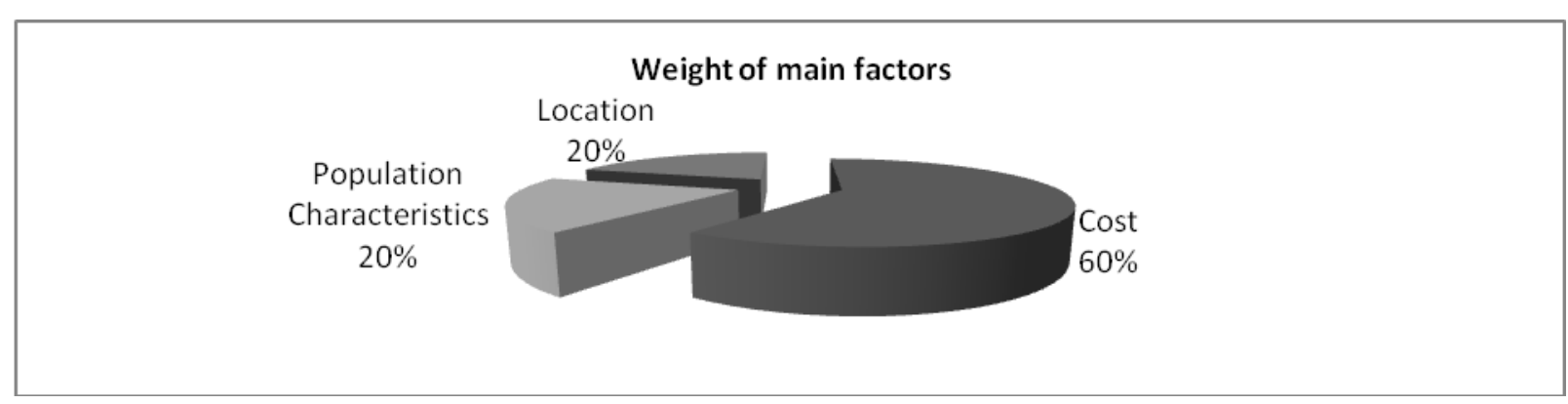


Table 8: Importance of sub factors

\begin{tabular}{|c|c|c|c|c|}
\hline Sub factors & $\begin{array}{l}\text { Weight of sub } \\
\text { factors }\end{array}$ & $\begin{array}{l}\text { Impact within the } \\
\text { main factor (in \%) }\end{array}$ & $\begin{array}{l}\text { Overall weight of } \\
\text { sub factors }\end{array}$ & $\begin{array}{l}\text { Overall Impact of } \\
\text { the sub factor (in } \\
\% \text { ) }\end{array}$ \\
\hline Cost of land & 0.608 & 60.795 & 0.3648 & 36.477 \\
\hline Land Topography & 0.122 & 12.159 & 0.0730 & 7.295 \\
\hline Land ownership & 0.172 & 17.159 & 0.1030 & 10.295 \\
\hline Running/ Maintenance cost & 0.099 & 9.886 & 0.0593 & 5.932 \\
\hline Population density & 0.655 & 65.549 & 0.1311 & 13.110 \\
\hline Education & 0.158 & 15.776 & 0.0316 & 3.155 \\
\hline Economic condition & 0.187 & 18.675 & 0.0373 & 3.735 \\
\hline Proximity to Public transport & 0.454 & 45.379 & 0.0908 & 9.076 \\
\hline Space for future construction & 0.192 & 19.242 & 0.0385 & 3.848 \\
\hline Availability of existing infrastructure & 0.078 & 7.803 & 0.0156 & 1.561 \\
\hline Proximity to market & 0.276 & 27.576 & 0.0552 & 5.515 \\
\hline
\end{tabular}

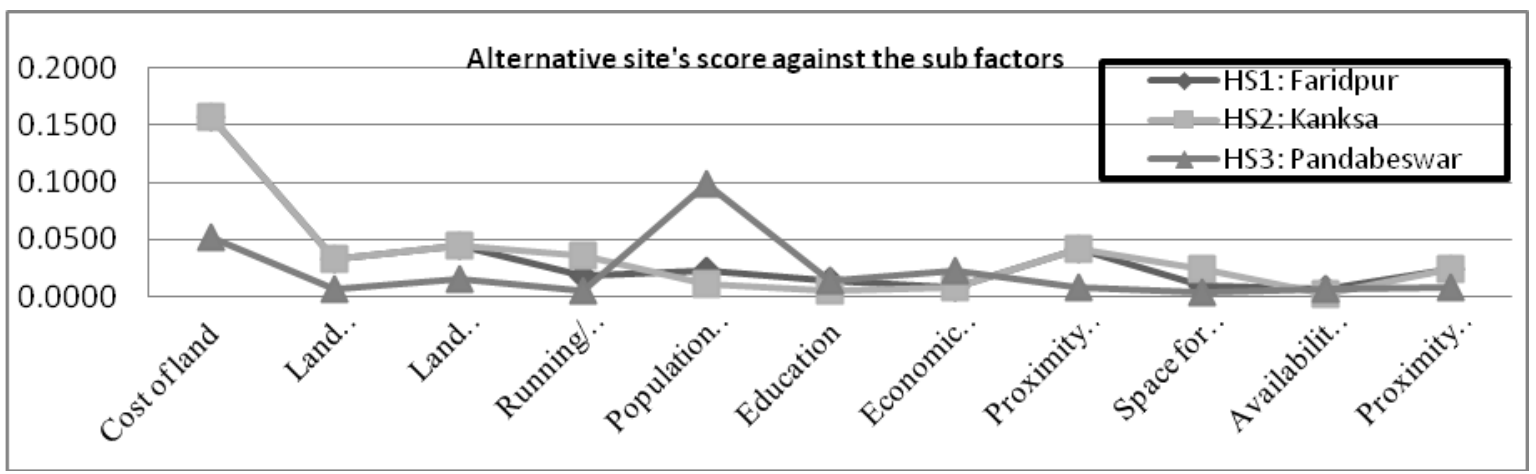

Figure 5: Scores of the alternative sites against the sub factors

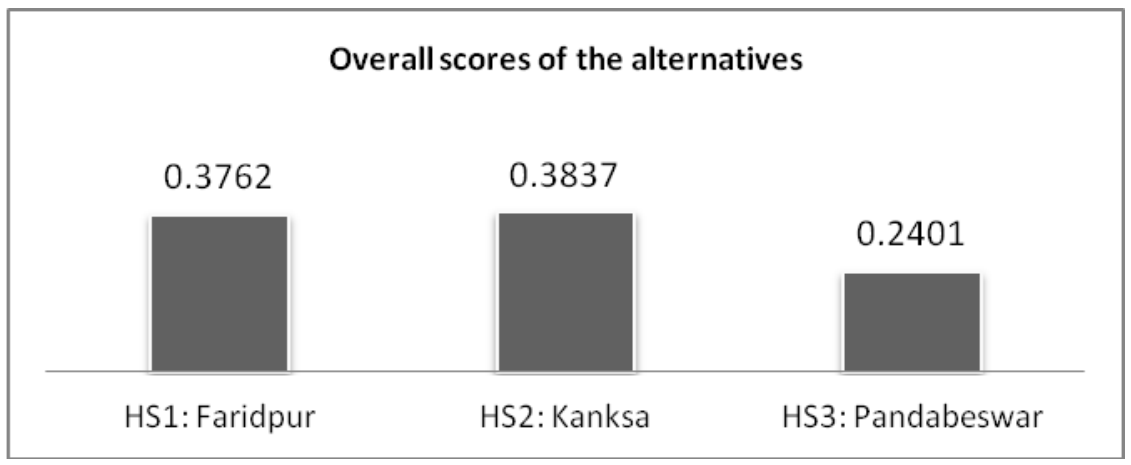

Figure 6: Overall score of the alternatives

\section{CONCLUSION}

In recent past few studies related to multi criteria evaluation of hospital sites are availablein literatureusing different methodologies including AHP, but the present study never came across any Indian studyon hospital site selection. In this piece of work the objective wasalso to arrive at a consensus among expert opinions before processing the data using pair wise comparison matrices. However one can argue that average of all responses could have been taken, but the researcher is of the view that average would normalize the quality of expert feedback and may fail to provide higher precision.Soltani et al. also is of the opinion that a higher accuracy can be achieved by using structured methods of consensus development [24].This proposed model can be used by the planners or administrators as a prototype before getting 
into such health care projects. From the results it is visible that the factor 'cost' appears to be the most significant contributor in the site selection exercise where 'travel time' emerged as the most important factor in other studies ([26]; [24], [29]). Since the present study has been conducted to select a location for potential hospital inrural India, with a difference in culture and economy the result is quite acceptable. Interestingly, the factor 'population density' emerged as the second highest important factor across all the three studies and therefore proves it's importance as a major factor in the selection. Further, this study also reveals a positive association between the land cost, population density and proximity to public transport.

Although AHP is anefficient tool in capturing subjective judgments in multi criteria decision making environment, the computation becomes huge if more number of alternatives or factors is considered in a study.However, use of software can reduce the degree of computation to some extent.For future research one can use AHPin the location selection for different specialty hospitals with a varied set of factors and sub factors of evaluation and can also check the importance of different factors with respect to different category of hospitals.

\section{REFERENCES}

[1] Altay, A. 2008.A Rating Approach to the Solutions of Istanbul Traffic.in IEMC Europe 2008: Proceedings of Engineering Management Conference, pp. 1-4. (Accessed on 26 Dec 2009, http://ieeexplore.ieee.org)

[2] Atthirawong, W and McCarthy, B. 2002. An Application of the Analytical Hierarchy Process to International Location Decision-Making. Proceedings of 7 th annual Cambridge International Manufacturing Symposium: Restructuring overall manufacturing, University of Cambridge, England, pp. 1-18.

[3] Grandzol J.R. 2005. Improving the Faculty Selection Process in Higher Education: A Case for the Analytic Hierarchy Process.paper presented at Association for Institutional Research, Bloomsburg University of Pennsylvania, Pennsylvania, United States, 24 August, 2005.

[4] Grewal, C.S., Sareen, K.K. and Gill, S. 2008. A multifactor logistic outsourcing decision making using the analytic hierarchy process.International Journal of Services Technology and Management, Vol. 9, No. 1, pp. $1-13$.

[5] Guagliardo, M. 2004. Spatial accessibility of primary care: concepts, methods and challenges.International Journal of Health Geographics, Vol. 3, No. 3, pp 1-13.

[6] Hanes, P. J. and McKnight, C.M. 1984.Criteria for selection of a practice location among senior dental students at the University of Mississippi.Journal of Dental Education, Vol. 48, No. 2, pp. 102-104.

[7] Jesuk, K. 2005. Solving distribution facility location problem using an analytic hierarchy process approach.Paper presented at ISAHP, Honolulu, Hawaii, 8-10 July 2005.

[8] Jordan, H.,Roderick, P., Martin, D. and Barnett, S. 2004. Distance, rurality and the need for care: access to health services in South West England.International Journal of Health Geographics, Vol. 3, No. 21, pp. 1-9.
[9] Korkmaz, I., Hadi, G. and Tahsin, C. 2008. An analytic hierarchy process and two-sided matching based decision support system for military personnel assignment.Information Sciences, Vol. 178 No. 14, pp. 2915-2927.

[10] Kuo, R., Chi, S. and Kao, S. 1999. A decision support system for locating convenience store through fuzzy AHP.Computers \& Industrial Engineering, Vol. 37 No. 3, pp. 323-326.

[11] Medical facility: Burdwan district. http://www.bardhaman.gov.in/health/medifaci.html (Accessed on 31st January 2013)

[12] Mehrez, A.,Sinuany-Stern, Z., Arad-Geva, T. and Binyamin, S. 1996. On the Implementation of Quantitative Facility Location Models: The Case of a Hospital in a Rural Region.The Journal of the Operational Research Society, Vol. 47 No. 5, pp. 612 625.

[13] Ozden, B. and Birsen, K. 2005.An AHP application in vendor selection. Presented at ISAHP 2005, Honolulu, Hawaii, 8-10 July 2005.

[14] Paul, A.J. and Batta, R. 2008.Models for hospital location and capacity allocation for an area prone to natural disasters.International Journal of operations research, Vol.3 No. 5, pp. 473-496.

[15] Paul, D.P. 1997. Dental practice location: Some aspects of the importance of selection of place.Health Marketing Quarterly, Vol. 14 No. 4, pp. 55-69.

[16] Pavlikakis, G.E. and Tsihrintzis, V.A. 2003. Evaluation of three multi-factor methods in ecosystem management. Proceedings of the 8th International Conference on Environmental Science and Technology, Lemnos Island, Greece, 8 -10 September 2003.

[17] Population: Burdwan district, http://www.bardhaman.gov.in/census/popliterate.html (Accessed on 31st January 2013).

[18] Project Charter Site Validation, Children's Hospital of Saskatchewan, 2010 , http://chssitevalidation.files.wordpress.com/2010/02/proj ect-charter2.pdf, (Accessed on $24^{\text {th }}$ December 2012).

[19] Saaty, T.L. 2000. Fundamentals of Decision Making and Priority Theory, 2nd ed.,RWS Publications, Pittsburgh.

[20] Saaty, T.L. 1980.The Analytic Hierarchy Process, Planning, Priority Setting, Resource Allocation, McGraw Hill, New York, 1980.

[21] Schuurman, N., Fiedler, R.S., Grzybowski, S., and Grund, D. 2006. Defining rational hospital catchments for non-urban areas based on travel-time. International Journal of Health Geographics,http://www.ijhealthgeographics.com/content/5/1/43(Accessed on 24th December 2012)

[22] Shim, J. P.1989. Bibliographical research on the analytic hierarchy process (AHP).Socio-Economic Planning Sciences, Vol. 23 No. 3,pp. 161-167.

[23] Sinimole, K.R. 2012, Performance evaluation of the hospital services - a fuzzy analytic hierarchy process model, International Journal of Productivity and Quality Management, Vol. 10 No. 1, pp.112-130. 
[24] Soltani, A., Marandi, E.Z. 2011.Hospital site selection using two stage fuzzy multi-criteria decision making process.Journal of Urban andenvironmental engineering, Vol. 5 No. 1, pp. 32-43.

[25] Triantaphyllou, E. and Mann, S.H. 1995. Using the analytical hierarchy process for decision making in engineering applications: some challenges.International Journal of Industrial Engineering: Applications and Practice, Vol. 2 No. 1, pp. 35-44.

[26] Vahidnia, M.H., Alesheikh, A. and Alimohammadi, A. 2009. Hospital site selection using fuzzy AHP and its derivatives.Journal of environmental management, Vol. 90 No. 10, pp. 3048-3056

[27] Varnakovida, P. and Messina, J.P. 2006. Hospital Site Selection Analysis.In Proceedings of the IMAGIN annual

Conference,

2006

http://citeseerx.ist.psu.edu/viewdoc/summary?doi=10.1.1 .121 .4330 (Accessed on $24^{\text {th }}$ January 2013)

[28] World Health statistics 2012 http://www.who.int/gho/publications/world_health_statis tics/2012/en/index.html (accessed on 24th January 2013)

[29] Wu, C.R., Lin, C. and Chen, H. 2007. Optimal selection of Taiwanese hospitals to ensure a competitive advantage by using analytical hierarchy process and sensitivity analysis.Building and environment, Vol. 42 No. 3, pp. $1431-1444$

[30] Yang, J. and Shi, P. 2002. Applying Analytic Hierarchy Process in Firm's Overall Performance Evaluation: A Case Study in China.International Journal of Business, $\begin{array}{lllll}\text { Vol. } & 7 \text { No. } & 1, & \text { pp. }\end{array}$ 